\title{
How to Profit From Declines of Share Prices without Shorting Them
}

\author{
Leszek Zaremba
}

Correspondence: Leszek Zaremba, Institute of Management, Academy of Finance and Business Vistula, ul. Stoklosy 3, 02787 Warsaw, Poland

Received: December 5, 2017

Accepted: January 7, 2018

Online Published: January 11, 2018

doi:10.11114/bms.v4i1.2924

URL: https://doi.org/10.11114/bms.v4i1.2924

\begin{abstract}
We present a 1-period model of the Polish financial market from the view point of the largest Polish company KGHM, whose share prices declined from 119 PLN on June 1, 2015 to 68 PLN on December 2, 2015. Our goal is to show how KGHM might create portfolios (with practically zero cost), which would (almost) fully compensate these declines without, what is very important, short sale of KGHM's shares. The presented methodology is equally suitable in any country for all those companies for which options on their shares are also tradable. We employ here a matrix model of a fraction of the Polish financial market and make use of the Black-Scholes formula to valuate 3 portfolios replicating 3 desired by KGHM, but not available on the market, financial instruments. To give more insight to the readers, we distinguish two cases. In one of them, volatility of KGHM's share prices is $35 \%$, and in the other case it equals $20 \%$.
\end{abstract}

Keywords: approximate hedging, Black-Scholes formula, incomplete market, replication error, share prices

JEL: C02, C18, C54, C60

\section{Introduction}

The motivation for writing this article came from observation that several listed companies from time to time suffer huge declines in their share prices. Our goal is to show how KGHM, one of the largest cooper and silver producers in the world, might create an extra income from a hedging portfolio which would fully compensate potential declines of its share prices. The presented methodology works even better for external (other than KGHM) investors. In this article we improve the results obtained in (Zaremba 2016, 2017a), by avoiding the short sale of KGHM shares which was a kind of shortcoming in these articles.

Our goal is to show how any company (KGHM is just a randomly chosen company) might create portfolios (with cost close to zero) which would (almost) fully compensate potential declines of its share price without, what is very important, short sale of its shares. The presented methodology is equally suitable in any country for all such companies for which options on their shares are tradable.

The topic discussed in this paper belongs to the research area called static hedging in complete and incomplete markets. There is a number of articles published already which are devoted to this field, but none of them (to the knowledge of this author) is focused on the issue of compensating declines of share prices. As a matter of fact, we do not cite these works because the ideas, theories, or research contained in them in no way influenced our study.

Similarly as in (Cerny 2009, pp.1-21) we present a 1-period model of a fraction of the Polish financial market in which there are only 2 dates, today and "tomorrow", the latter may mean this week or next month or next quarter, etc. In such model it is assumed that all economic activity (consumption, trading and work) takes place only today and "tomorrow". It turns out that such a model quite adequately represents the real financial market for many medium-term or long-term investors, such as for example investment funds.

In this 1-period model vectors represent financial instruments, such as the vector $\mathbf{b}$ below, while matrices represent financial markets, with their columns featuring payments from all liquid securities on a particular market under consideration. An example of such a matrix is P given by (1), which is more complex than the ones investigated in (Zaremba 2016, p.504; 2017a, p.25) and in Zaremba (in press). P represents a fraction of the Polish financial market from the point of view KGHM, with first column b displaying payments resulting from 1 KGHM's share in 7 different scenarios: 


$$
\mathbf{b}=\left[\begin{array}{c}
55 \\
70 \\
85 \\
100 \\
115 \\
130 \\
145
\end{array}\right] ; \quad \mathrm{P}=\left[\begin{array}{cccc}
55 & 100 & 0 & 55 \\
70 & 100 & 0 & 35 \\
85 & 100 & 0 & 20 \\
100 & 100 & 5 & 5 \\
115 & 100 & 20 & 0 \\
130 & 100 & 35 & 0 \\
145 & 100 & 50 & 0
\end{array}\right]
$$

Matrix P displays all possible payments in 7 scenarios on December 2, 2015 ("tomorrow") resulting from 4 different financial instruments bought "today", that is on June 1, 2015. Columns 2, 3, and 4 represent payments generated respectively by a treasury bill, a call option at strike price of 95 PLN, and a put option at strike price of 110 PLN.

\section{Problem Statement}

To make our model more realistic, we associate certain probabilities, say $\mathrm{p}=\left[\begin{array}{l}0,06 \\ 0,09 \\ 0,13 \\ 0,17 \\ 0,25 \\ 0,19 \\ 0,11\end{array}\right]$ to 7 states of the market (7 scenarios) of the Polish financial market. Our goal is to suggest what portfolio should KGHM hold in order (i) to be compensated for all potential declines of its share prices, and (ii) to pay very little for such portfolio without necessity of shorting its own shares. The same financial profits will achieve any other (than KGHM) investor by holding the portfolio specified below.

We take into account that prices of KGHM's shares may decline to 55 PLN in a 6-month horizon (in fact, they declined to 65 PLN on December 2, 2015) from the current level of 119 PLN on June 1, 2015, as well as they may rise up to 145 PLN in a 6-month period.

\section{Some Theory}

The underlying theory was first presented in (Cerny, 2009, pp. 25-49) and then was employed also in (Zaremba, 2016, 2017a, 2017b) and Zaremba (in press). Generally speaking, it is supposed that a financial market is represented by some $m \times n$ matrix, say $A=\left[\begin{array}{cccc}A_{11} & A_{12} & \ldots & A_{1 n} \\ A_{21} & A_{22} & \cdots & A_{2 n} \\ \ldots & \ldots & \ldots & \cdots \\ A_{m 1} & A_{m 2} & \ldots & A_{m n}\end{array}\right]$, with vector $\mathbf{b}=\left[\begin{array}{c}b_{1} \\ b_{2} \\ \vdots \\ b_{m}\end{array}\right]$ featuring a desired financial instrument (focus asset) compensating perfectly or almost perfectly potential declines of a certain company's shares. If market A is incomplete, that is, not all instruments (such as b) can be perfectly replicated by basis assets (columns of matrix A), then the question arises how one

can build the best approximate hedge of the focus asset $\mathbf{b}$ by means of a portfolio $\mathrm{x}=\left[\begin{array}{c}x_{1} \\ x_{2} \\ \vdots \\ x_{n}\end{array}\right]$ consisting of columns of matrix A in such a way that its replication error should be as small as possible. Incomplete markets were discussed in Zaremba (2017b, pp. 119-121). Below SSRE is the abbreviation for "sum of squared replication errors". We thus have

$$
\operatorname{SSRE}=\varepsilon_{1}{ }^{2}+\varepsilon_{2}{ }^{2}+\ldots+\varepsilon_{\mathrm{m}}{ }^{2}=\left[(\mathrm{Ax})_{1}-\mathrm{b}_{1}\right]^{2}+\left[(\mathrm{Ax})_{2}-\mathrm{b}_{2}\right]^{2}+\ldots+\left[(\mathrm{Ax})_{\mathrm{m}}-\mathrm{b}_{\mathrm{m}}\right]^{2}
$$

with $\varepsilon=\left(\varepsilon_{1}, \varepsilon_{2}, \ldots, \varepsilon_{\mathrm{m}}\right)=\mathrm{Ax}-\mathrm{b}$. Since some states of the world are less likely than others, the company should be interested in the expected SSRE, ESSRE for short, where

$\operatorname{ESSRE}=\mathrm{p}_{1} \varepsilon_{1}{ }^{2}+\mathrm{p}_{2} \varepsilon_{2}{ }^{2}+\ldots+\mathrm{p}_{\mathrm{m}} \varepsilon_{\mathrm{m}}{ }^{2}=\mathrm{p}_{1}\left[(\mathrm{Ax})_{1}-\mathrm{b}_{1}\right]^{2}+\mathrm{p}_{2}\left[(\mathrm{Ax})_{2}-\mathrm{b}_{2}\right]^{2}+\ldots \mathrm{p}_{\mathrm{m}}\left[(\mathrm{Ax})_{\mathrm{m}}-\mathrm{b}_{\mathrm{m}}\right]^{2}$, with $\mathrm{p}_{1}>0, \mathrm{p}_{2}>0, \ldots, \mathrm{p}_{\mathrm{m}}>$ 0 standing for objective probabilities of the individual states of the world; $m$ denotes the number of rows (scenarios) that may take place in our model. 


\section{Definition 1}

A general hedging (replication) problem $\mathrm{Ax}=\mathbf{b}$ consists in finding such portfolio $\hat{\mathrm{X}}$ that $\mathrm{A} \hat{\mathrm{X}}$ is as close to the focus asset $\mathbf{b}$ as possible in the sense of minimization of SSRE, or ESSRE if probabilities of states of the market are given.

The following result can be found in (Cerny, 2009, pp. 30-34).

\section{Theorem 1}

Consider a general hedging problem $A x=\mathbf{b}$. Define a new matrix $\tilde{A}$ and a new vector $\tilde{b}$ by multiplying each row of $A$ and $\mathbf{b}$ by the square root of the probability $p_{1}$ for the corresponding state. The optimal hedging portfolio that minimizes ESSRE is of the form $\hat{x}=\left[\tilde{A}^{T} \tilde{A}\right]^{-1} \tilde{A}^{T} \tilde{b}$. Its payments are then given by vector $A \hat{x}=A\left[\tilde{A}^{T} \widetilde{A}\right]^{-1} \widetilde{A}^{T} \tilde{b}$ which replicates $\mathbf{b}$ in the best possible way.

\section{Determination of Hedging Portfolios with and without Short Sale of KGHM's Shares}

Suppose that today is June 1, 2015 and the price of 1 KGHM's share is 119 PLN. With matrix P representing a fraction of the Polish financial market, we are looking for financial instruments which will compensate potential declines of KGHM's share prices in the period of nearest 6 months. An example of such compensating instrument is the focus asset $\mathbf{f}=\left[\begin{array}{c}65 \\ 50 \\ 35 \\ 20 \\ 5 \\ -10 \\ -25\end{array}\right]$. In this case, having in mind that 1 KGHM's share pays $\mathbf{b}=\left[\begin{array}{c}55 \\ 70 \\ 85 \\ 100 \\ 115 \\ 130 \\ 145\end{array}\right]$ in 7 states of the Polish financial market, each holder of asset $\mathbf{f}$ and 1 share of KGHM's share is guaranteed the risk-free income of 120 in all 7 scenarios in the beginning of December 2015. Buying on June 1, 2015 portfolio $\mathbf{x}=\left[\begin{array}{c}-1 \\ 1.2 \\ 0 \\ 0\end{array}\right]$ the investor (KGHM or any other one) will replicate the focus asset $\mathbf{f}$, and will get rid of any risk.

However, portfolio $\mathbf{x}$ requires a short sale of 100\% of KGHM's shares which are going to be protected against declines of their prices. Although this may be pretty much OK with some investors, it is not suitable for KGHM itself as it could suggest for current and potential investors serious problems in KGHM.

Before we go any further with our studies, it is good to notice that Theorem 1 produces the same solution $\mathbf{x}$, that is, the best approximating portfolio $\hat{x}=\left[\widetilde{P}^{T} \widetilde{P}\right]^{-1} \widetilde{P}^{T} \tilde{f}$ is exactly equal to $\left[\begin{array}{c}-1 \\ 1.2 \\ 0 \\ 0\end{array}\right]$. We leave this simple proof for the reader.

Therefore, now we will try another financial focus instrument compensating declines in KGHM's shares, such that the resulting portfolio will not involve short sale of KGHM' shares or it will involve the short sale to a small extend only.

Towards this end, let us try the focus instrument $f_{1}=\left[\begin{array}{c}69 \\ 43 \\ 37 \\ 23 \\ 2 \\ -14 \\ -23\end{array}\right]$. To calculate the resulting optimal portfolio $\hat{x}_{1}=\left[\tilde{P}^{T} \tilde{P}\right]^{-1} \cdot\left[\tilde{P}^{T} \tilde{f}_{1}\right]$ we will compute first matrices $\tilde{P}^{T},\left[\tilde{P}^{T} \tilde{P}\right] ;\left[\tilde{P}^{T} \tilde{P}\right]^{-1}$ which do not depend on the chosen

financial instrument $\mathbf{f}$, a next determine $\tilde{f}_{1}$ and $\tilde{P}^{T} \tilde{f}_{1}$. By doing so, we will be obtaining in sequence 
$\tilde{P}^{T}=\left[\begin{array}{ccccccc}55 \sqrt{0.06} & 70 \sqrt{0.09} & 85 \sqrt{0.13} & 100 \sqrt{0.17} & 115 \sqrt{0.25} & 130 \sqrt{0.19} & 145 \sqrt{0.11} \\ 100 \sqrt{0.06} & 100 \sqrt{0.09} & 100 \sqrt{0.13} & 100 \sqrt{0.17} & 100 \sqrt{0.25} & 100 \sqrt{0.19} & 100 \sqrt{0.11} \\ 0 & 0 & 0 & 5 \sqrt{0.17} & 20 \sqrt{0.25} & 35 \sqrt{0.19} & 50 \sqrt{0.11} \\ 55 \sqrt{0.06} & 40 \sqrt{0.09} & 25 \sqrt{0.13} & 10 \sqrt{0.17} & 0 & 0 & 0\end{array}\right]=$
$\left[\begin{array}{cccccccc}13.47 & 21 & 30.65 & 41.23 & 57.5 & 56.67 & 48.09 \\ 24.49 & 30 & 36.06 & 41.23 & 50 & 43.59 & 33.17 \\ 0 & 0 & 0 & 2.06 & 10 & 15.26 & 16.58 \\ 13.47 & 12 & 9.01 & 4.12 & 0 & 0 & 0\end{array}\right], \tilde{P}^{T} \tilde{P}=\left[\begin{array}{cccc}12092 & 10705 & 2322 & 879.5 \\ 10705 & 10000 & 1800 & 1185 \\ 2322 & 1800 & 612 & 8.5 \\ 879.5 & 1185 & 8.5 & 423.75\end{array}\right]$
$\left[\tilde{P}^{T} \tilde{P}\right]^{-1}=\left[\begin{array}{cccc}0.1795 & -0.182 & 0.146 & 0.1406 \\ -0.182 & 0.186 & 0.147 & -0.145 \\ -0.146 & 0.147 & 0.1264 & -0.109 \\ 0.1406 & -0.145 & -0.109 & 0.1173\end{array}\right], \tilde{f}_{1}=\left[\begin{array}{c}16.90 \\ 12.90 \\ 13.34 \\ 9.48 \\ 1 \\ -6.10 \\ -7.63\end{array}\right], \tilde{P}^{T} \tilde{f}_{1}=\left[\begin{array}{c}643 \\ 1204 \\ -190 \\ 542\end{array}\right]$ Finally, based on Theorem 1, we arrive at the desired portfolio

$$
\hat{x}_{1}=\left[\tilde{P}^{T} \tilde{P}\right]^{-1} \cdot\left[\tilde{P}^{T} \tilde{f}_{1}\right]=\left[\begin{array}{c}
-0.263 \\
0.445 \\
-0.631 \\
0.593
\end{array}\right]
$$

which in the best possible way approximates the focus asset $\mathbf{f}_{1}$, taking into account the assumed probabilities $\mathbf{p}=\left[\begin{array}{l}0,06 \\ 0,09 \\ 0,13 \\ 0,17 \\ 0,25 \\ 0,19 \\ 0,11\end{array}\right]$ of the 7 states of the market. The obtained portfolio will be therefore worth

$$
\boldsymbol{P} \cdot \hat{\boldsymbol{x}}_{1}=\left[\begin{array}{cccc}
55 & 100 & 0 & 55 \\
70 & 100 & 0 & 35 \\
85 & 100 & 0 & 20 \\
100 & 100 & 5 & 5 \\
115 & 100 & 20 & 0 \\
130 & 100 & 35 & 0 \\
145 & 100 & 50 & 0
\end{array}\right] \cdot\left[\begin{array}{c}
-0.263 \\
0.445 \\
-0.631 \\
0.593
\end{array}\right]=\left[\begin{array}{c}
62.6 \\
49.8 \\
37.0 \\
21.0 \\
1.7 \\
-11.7 \\
-25.1
\end{array}\right] \text { PLN, }
$$

depending on the state of the market in the beginning of December 2015. Together with 1KGHM's share (the first column in matrix P), the instrument $\mathbf{f}_{1}$ will generate payoffs $\left[\begin{array}{l}117.63 \\ 119.80 \\ 121.98 \\ 120.99 \\ 116.67 \\ 118.27 \\ 119.87\end{array}\right]$ whose expected value (taking into account probabilities $\mathbf{p}$ of the 7 states of the market) equals 119.09 PLN, slightly more than the initial price (119 PLN).

\section{Corollary 1}

If on June 1, 2015 an investment fund or any other investor including KGHM itself wished to protect the value of 100,000 of KGHM's shares against their declines in the 6-month period, then each of them on June 1 should (i) short 26,266 KGHM shares, (ii) hold 44,488 six- month treasury bills, (iii) short 63,066 six-month call options on 1 KGHM' share with a strike price of 95 PLN, and (iv) buy 59,258 six-month put options on 1 KGHM' share with strike price of 110 PLN. 


\subsection{Determination of Hedging Portfolios without Short Sale of KGHM's Shares}

Let's therefore try another financial instrument, call it $\mathrm{f}_{2}$, with the aim of creating its (i) best approximate hedge (replica) $\hat{x}_{2}=\left[\tilde{P}^{T} \widetilde{P}\right]^{-1} \cdot\left[\tilde{P}^{T} \tilde{f}_{2}\right]$ which will not involve short sale of KGHM's shares. Since matrices $\tilde{\mathrm{P}}$, [ $\left.(\widetilde{\mathbf{P}})^{\mathrm{T}} \widetilde{\mathbf{P}}\right]$, as well as $\left[(\widetilde{\mathbf{P}})^{\mathrm{T}} \widetilde{\mathbf{P}}\right]^{-1}$ remain the same as in case of $\mathrm{f}_{1}$ (they have nothing to do with $\mathrm{f}_{1}$ and $\mathrm{f}_{2}$ ), we only need to calculate vectors $\tilde{f}_{2}$ and $\tilde{P}^{T} \tilde{f}_{2}$. Making use of Excel, after a few trials, we suggest financial instrument

$\mathbf{f}_{2}=\left[\begin{array}{c}61 \\ 42 \\ 33 \\ 25 \\ 3.4 \\ -13 \\ -17\end{array}\right]$ for which we compute $\tilde{f}_{2}=\left[\begin{array}{c}14.94 \\ 12.60 \\ 11.90 \\ 10.31 \\ 2 \\ -5.67 \\ -5.64\end{array}\right]$ and $\tilde{P}^{T} \tilde{f}_{2}=\left[\begin{array}{c}761 \\ 1249 \\ -142 \\ 502\end{array}\right]$. The latter vector appeared to be similar to $\tilde{P}^{T} \tilde{f}_{1}=\left[\begin{array}{c}643 \\ 1204 \\ -190 \\ 542\end{array}\right]$. The resulting optimal portfolio $\hat{x}_{2}$ is, however, quite different than $\hat{x}_{1}, \quad$ namely $\hat{\mathrm{x}}_{2}=\left[\widetilde{P}^{T} \widetilde{P}\right]^{-1} \cdot\left[\widetilde{P}^{T} \widetilde{f}_{2}\right]=\left[\begin{array}{c}0.022 \\ 0.164 \\ -0.807 \\ 0.697\end{array}\right]$ what means that short sale of KGHM's shares has been avoided. In Section 5 we will show that the cost of acquiring portfolio $\hat{x}_{2}$ is close to zero, depending on the dividend yield paid by KGHM to its shareholders.

\section{Corollary 2}

If on June 1, 2015 an investor wished to protect the value of 100,000 of KGHM's shares against their declines in the 6-month period, then on that day he should (i) hold just 2200 of KGHM shares, (ii) hold 16,400 six- month treasury bills, (iii) short 80,700 six-month call options on 1 KGHM' share with a strike price of 95 PLN, and (iv) buy 69,700 six-month put options on 1 KGHM' share with strike price of 110 PLN.

Before we proceed to the next section, let us again make use of Excel. After few trials, we have found the financial instrument $\mathbf{f}_{3}=\left[\begin{array}{c}63 \\ 45 \\ 37 \\ 25 \\ 2 \\ -18 \\ -25\end{array}\right]$ for which $\tilde{f}_{3}=\left[\begin{array}{c}15.43 \\ 13.50 \\ 13.34 \\ 10.31 \\ 1 \\ -7.85 \\ -8.29\end{array}\right]$ and $\tilde{P}^{T} \tilde{f}_{3}=\left[\begin{array}{c}539 \\ 1122 \\ -226 \\ 533\end{array}\right]$. The resulting optimal portfolio $\hat{x}_{3}$ is similar to $\hat{x}_{2}$, and also without a short sale of KGHM's shares, namely $\hat{\boldsymbol{x}}_{3}=\left[\widetilde{\boldsymbol{P}}^{T} \widetilde{\boldsymbol{P}}\right]^{-1} \cdot\left[\widetilde{\boldsymbol{P}}^{T} \tilde{\boldsymbol{f}}_{3}\right]=\left[\begin{array}{c}0.009 \\ 0.200 \\ -1.001 \\ 0.700\end{array}\right]$. However, it is cheaper than portfolio $\hat{x}_{2}$, what will be demonstrated in the Section 5 .

\section{Corollary 3}

If on June 1, 2015 an investor wished to protect the value of 100,000 of KGHM's shares against their declines in the 6-month period, then on June 1 he should (i) hold just 900 of KGHM shares, (ii) hold 20,000 six- month treasury bills, (iii) short 100,100 six-month call options on 1 KGHM' share with a strike price of 95 PLN, and (iv) buy 70,000 six-month put options on 1 KGHM' share with strike price of 110 PLN.

\section{Valuation of Call and Put Options (Volatility $\sigma=35 \%$; Risk-Free Rate $\mathbf{r}=\mathbf{2 . 5 \%}$ )}

In order to estimate the (theoretical) market price of portfolios $\hat{x}_{1}, \hat{x}_{2}, \hat{x}_{3}$ on June 1,2015 , let's start with computation of theoretical market prices of the 4 basis assets they are build upon(see definition of matrix $\mathrm{P}$ at the end of Introduction). We already know that 1 KGHM's share costs 119 PLN. Since the risk-free rate in Poland is $2.5 \%-3 \%$ per annum, one may assume that a 6-month treasury bill with face value of 100 PLN (our second basis asset) has the market 
price between 98.50 PLN and 99 PLN.

What remains to do, is the estimation of theoretical market price of (i) a 6-month call option $c_{95}$ with strike 95 PLN and (ii) a 6-month put option $p_{110}$ with strike 110 PLN. According to Black-Scholes formula the theoretical value of a call option is given by

$$
\mathrm{c}=S \exp (-q T) N\left(d_{1}\right)-X \exp (-r T) N\left(d_{2}\right)
$$

where $\mathrm{q}$ is dividend yield (for better illustration we suppose that $\mathrm{q}$ was between $2 \%$ and $4 \%$ in the last few years), $\mathrm{T}$ is the expiration date $\left(\frac{1}{2}\right.$ of the year in the studied case), $\mathrm{N}(\mathrm{d})$ is the cumulative probability distribution function for the standard normal distribution $\mathrm{N}(0,1), \mathrm{r}$ is the risk-free rate on Polish market (about $2.5 \%$ annually), with

$$
\mathrm{d}_{1}=\left[\ln (\mathrm{S} / \mathrm{X})+\left(\mathrm{r}-\mathrm{q}+0,5 \sigma^{2}\right] / \sigma \sqrt{\mathrm{T}} ; \mathrm{d}_{2}=\left[\ln (\mathrm{S} / \mathrm{X})+\left(\mathrm{r}-\mathrm{q}-0,5 \sigma^{2}\right] / \sigma \sqrt{\mathrm{T}} .\right.\right.
$$

Let's see how different values of parameter q affect the valuation of our call option with strike price 95 PLN. When q = $2 \%$ then $\mathrm{d}_{1}=1.0440, \mathrm{~d}_{2}=0.7965$ and consequently $\mathrm{N}\left(\mathrm{d}_{1}\right)=0.852, \mathrm{~N}\left(\mathrm{~d}_{2}\right)=0.7871$ so that $c_{95}=26.50$ PLN.

When dividend yield is higher, for example, $\mathrm{q}=3 \%$, then $\mathrm{d}_{1}=1.0238, \mathrm{~d}_{2}=0.7763$ and consequently $\mathrm{N}\left(\mathrm{d}_{1}\right)=$ $0.8470, \mathrm{~N}\left(\mathrm{~d}_{2}\right)=0.7812$ so that $c_{95}=26.00$ PLN. Finally, when $\mathrm{q}=4 \%$ then $\mathrm{d}_{1}=1.0036, \mathrm{~d}_{2}=0.7561$ and consequently $\mathrm{N}\left(\mathrm{d}_{1}\right)=0.8422, \mathrm{~N}\left(\mathrm{~d}_{2}\right)=0.7752$ so that the call option is even more cheaper, namely it costs $c_{95}=$ 25.51 PLN. We have just proved the following.

\section{Proposition 1}

The change of parameter q from $2 \%$ to $3 \%$ and next to $4 \%$ implies the corresponding change (decline) of $c_{95}$ :

\begin{tabular}{cccc}
\hline $\mathrm{q}=2 \%$ & $\mathrm{q}=3 \%$ & $\mathrm{q}=4 \%$ \\
\hline$c_{95}=26.50 \mathrm{PLN}$ & $c_{95}=26.00$ & PLN & $c_{95}=25.51$ PLN
\end{tabular}

Now, let's see how different values of parameter q affect the value of our put option with strike price of 110 PLN for which we have a slightly different Black-Scholes valuation formula

$$
\mathrm{p}=\operatorname{Sexp}(-\mathrm{qT}) \mathrm{N}\left(-\mathrm{d}_{1}\right)+\mathrm{X} \exp (-\mathrm{rT}) \mathrm{N}\left(-\mathrm{d}_{2}\right)
$$

When dividend $q=2 \%$ then $d_{1}=0.4516, d_{2}=0.2041$ and consequently $N\left(d_{1}\right)=0.6742, \quad N\left(d_{2}\right)=0,5809$ so that $\mathrm{p}_{115}=7,15$ PLN. When dividend is higher, for example $\mathrm{q}=3 \%$, then $\mathrm{d}_{1}=0.4314, \mathrm{~d}_{2}=0.1839$ and consequently $\mathrm{N}\left(\mathrm{d}_{1}\right)=0.6669, \mathrm{~N}\left(\mathrm{~d}_{2}\right)=0.5730$ so that $\mathrm{p}_{110}=7.34$ PLN.

The put option costs more when dividend yield is higher because it gives the right to sell for the same price (110 PLN) a less valuable share of KGHM (due to a higher payment of dividend from that share in the period June 1, 2015 to December 2, 2015). Finally, when $\mathrm{q}=4 \%$ then $\mathrm{d}_{1}=0.4112, \mathrm{~d}_{2}=0.1637$ and consequently $\mathrm{N}\left(\mathrm{d}_{1}\right)=0.6595$, $\mathrm{N}\left(\mathrm{d}_{2}\right)=0.5650$ so that $\mathrm{p}_{110}=7.54 \mathrm{PLN}$. We have just proved the following

\section{Proposition 2}

The change of parameter $\mathrm{q}$ from $2 \%$ to $3 \%$ and next to $4 \%$ implies the corresponding increase of $\mathrm{p}_{110}$ :

\begin{tabular}{c|c|c}
\hline $\mathrm{q}=2 \%$ & $\mathrm{q}=3 \%$ & $\mathrm{q}=4 \%$ \\
\hline $\mathrm{p}_{110}=7,15$ PLN & $\mathrm{p}_{110}=7.34$ PLN & $\mathrm{p}_{110}=7.54$ PLN \\
\hline
\end{tabular}

\subsection{Cost of the Hedging Portfolio $\hat{x}_{1}(\sigma=35 \%$; Risk-Free Rate $r=2.5 \%)$}

First we will estimate the cost of portfolio $\hat{x}_{1}=\left[\begin{array}{c}-0.263 \\ 0.445 \\ -0.631 \\ 0.593\end{array}\right]$ built upon 4 financial instruments (basis assets) represented by

4 columns of matrix $\mathrm{P}$ given by formula (1). Portfolio $\hat{x}_{1}$ is the best approximate hedge for financial instrument

$f_{1}=\left[\begin{array}{c}69 \\ 43 \\ 37 \\ 23 \\ 2 \\ -14 \\ -23\end{array}\right]$. When dividend yield $q=2 \%$, then $S=\left[\begin{array}{c}119 \\ 98.5 \\ 26.50 \\ 7.15\end{array}\right]$ designates the price vector of these 4 basis assets. The cost of 
$\hat{x}_{1}$ is therefore equal to $\left\langle S^{T} ; \hat{x}_{1}\right\rangle=\left[\begin{array}{c}119 \\ 98.5 \\ 26.50 \\ 7.15\end{array}\right]^{T}\left[\begin{array}{c}-0.263 \\ 0.445 \\ -0.631 \\ 0.593\end{array}\right]=0.09$ PLN, which represents only $0.1 \%$ of the KGHM's share price on June 1, 2015. Holding 1 KGHM's share plus financial instrument $\mathbf{f}_{\mathbf{1}}$ is almost risk-free investment since in the beginning of December 2015 it yields payoffs $\left[\begin{array}{l}117.63 \\ 119.80 \\ 121.98 \\ 120.99 \\ 116.67 \\ 118.27 \\ 119.87\end{array}\right]$. When dividend yield $\mathrm{q}=3 \%$, then $\mathrm{S}=\left[\begin{array}{c}119 \\ 98.5 \\ 26.00 \\ 7.34\end{array}\right]$ designates the price vector of the 4 basis assets. The cost of $\hat{x}_{1}$ is thus equal to $<S^{T} ; \hat{x}_{1}>=\left[\begin{array}{c}119 \\ 98.5 \\ 26.00 \\ 7.34\end{array}\right]\left[\begin{array}{c}-0.263 \\ 0.445 \\ -0.631 \\ 0.593\end{array}\right]=0.52$ PLN, which represents only $0.4 \%$ of 119 PLN. When dividend yield $q=4 \%$, then $S=\left[\begin{array}{c}119 \\ 98.5 \\ 25.51 \\ 7.54\end{array}\right]$ is the price vector of the 4 basis assets. The cost of $\hat{x}_{1}$ is thus equal to $\left\langle S^{T} ; \hat{x}_{1}>=\left[\begin{array}{c}119 \\ 98.5 \\ 25.51 \\ 7.54\end{array}\right]\left[\begin{array}{c}-0.263 \\ 0.445 \\ -0.631 \\ 0.593\end{array}\right]=0.94\right.$ PLN, which represents only 0.8\% of 119 PLN. The calculations above are summarized in

Table 1. Theoretical value of portfolio $\hat{x}_{1}$ in 3 different scenarios

\begin{tabular}{c|c|c}
\hline $\mathrm{q}=2 \%$ & $\mathrm{q}=3 \%$ & $\mathrm{q}=4 \%$ \\
\hline cost of $\hat{x}_{1}=0.09$ PLN & cost of $\hat{x}_{1}=0.52$ PLN & cost of $\hat{x}_{1}=0.94$ PLN \\
\hline
\end{tabular}

5.2 Cost of the Hedging Portfolio $\hat{x}_{2} \quad(\sigma=35 \%$; Risk-Free Rate $r=2.5 \%)$

Now we will estimate the cost of portfolio $\hat{x}_{2}=\left[\begin{array}{c}0.022 \\ 0.164 \\ -0.807 \\ 0.697\end{array}\right]$ which is the best approximate hedge for financial instrument $\mathbf{f}_{2}=\left[\begin{array}{c}61 \\ 42 \\ 33 \\ 25 \\ 3.4 \\ -13 \\ -17\end{array}\right]$. Let dividend yield $\mathrm{q}=2 \%$. Since the price vector of these 4 basis assets is the same, namely $\mathrm{S}=\left[\begin{array}{c}119 \\ 98.5 \\ 26.50 \\ 7.15\end{array}\right]$, the cost of $\hat{x}_{2}$ is equal to $\left\langle S^{T} ; \hat{x}_{2}>=\left[\begin{array}{c}119 \\ 98.5 \\ 26.50 \\ 7.15\end{array}\right]^{T}\left[\begin{array}{c}0.022 \\ 0.164 \\ -0.807 \\ 0.697\end{array}\right]=2.37\right.$ PLN, which represents $2 \%$ of the KGHM's share price on June 1, 2015. Holding 1 KGHM's share plus financial instrument $\mathbf{f}_{\mathbf{2}}$ is pretty risk-free investment since it will yield payoffs $\left[\begin{array}{l}110.95 \\ 115.83 \\ 120.70 \\ 121.54 \\ 117.79 \\ 121.01 \\ 124.24\end{array}\right]$ after 6 months (December 2, 2015). Let now dividend yield $q=3 \%$. Since the price vector of the 4 
basis assets $S=\left[\begin{array}{c}119 \\ 98.5 \\ 26.00 \\ 7.34\end{array}\right]$, the cost of $\hat{x}_{2}$ is equal to $\left\langle S^{T} ; \hat{x}_{2}>=\left[\begin{array}{c}119 \\ 98.5 \\ 26.00 \\ 7.34\end{array}\right]^{T}\left[\begin{array}{c}0.022 \\ 0.164 \\ -0.807 \\ 0.697\end{array}\right]=2.94\right.$ PLN, which represents $2.4 \%$ of 119 PLN. When dividend yield $q=4 \%$, then $S=\left[\begin{array}{c}119 \\ 98.5 \\ 25.51 \\ 7.54\end{array}\right]$ is the price vector of the 4 basis assets. The cost of $\hat{x}_{2}$ is equal to $\left\langle S^{T} ; \hat{x}_{1}>=\left[\begin{array}{c}119 \\ 98.5 \\ 25.51 \\ 7.54\end{array}\right]\left[\begin{array}{c}0.022 \\ 0.164 \\ -0.807 \\ 0.697\end{array}\right]=3.44\right.$ PLN, which represents only $2.9 \%$ of 119 PLN. The calculations above are summarized in

Table 2. Theoretical value of portfolio $\hat{x}_{2}$ in 3 different scenarios

\begin{tabular}{c|c|c}
\hline $\mathrm{q}=2 \%$ & $\mathrm{q}=3 \%$ & $\mathrm{q}=4 \%$ \\
\hline cost of $\hat{x}_{2}=2.37$ PLN & cost of $\hat{x}_{2}=2.94$ PLN & cost of $\hat{x}_{2}=3.44$ PLN \\
\hline
\end{tabular}

\subsection{Cost of the Hedging Portfolio $\hat{x}_{3}(\sigma=35 \%$; Risk-Free Rate $r=2.5 \%)$}

Finally, we will estimate the cost of portfolio $\hat{x}_{3}=\left[\begin{array}{c}0.009 \\ 0.200 \\ -1.001 \\ 0.700\end{array}\right]$ which is the best approximate hedge for financial instrument $\mathbf{f}_{3}=\left[\begin{array}{c}63 \\ 45 \\ 37 \\ 25 \\ 2 \\ -18 \\ -25\end{array}\right]$. Let again dividend yield $\mathrm{q}=2 \%$. Since the price of 4 basis assets are given as previously by vector $\mathrm{S}=\left[\begin{array}{c}119 \\ 98.5 \\ 26.50 \\ 7.15\end{array}\right]$, the cost of $\hat{x}_{3}$ is equal to $\left\langle S^{T} ; \hat{x}_{2}>=\left[\begin{array}{c}119 \\ 98.5 \\ 26.50 \\ 7.15\end{array}\right]^{T}\left[\begin{array}{c}0.009 \\ 0.200 \\ -1.001 \\ 0.700\end{array}\right]=-0.76\right.$ PLN, which represents $-0.6 \%$ of the KGHM's share price on June 1, 2015. Holding 1 KGHM's share plus financial instrument $\mathbf{f}_{3}$ is almost risk-free investment since it will yield payoffs $\left[\begin{array}{l}113.96 \\ 118.60 \\ 123.23 \\ 122.87 \\ 116.00 \\ 116.13 \\ 116.25\end{array}\right]$ on December 2, 2015. Let now dividend yield q =3\%. Since this time $S=\left[\begin{array}{c}119 \\ 98.5 \\ 26.00 \\ 7.34\end{array}\right]$, the cost of $\hat{x}_{3}$ is equal to $\left\langle S^{T} ; \hat{x}_{3}>=\left[\begin{array}{c}119 \\ 98.5 \\ 26.00 \\ 7.34\end{array}\right]^{T}\left[\begin{array}{c}0.009 \\ 0.200 \\ -1.001 \\ 0.700\end{array}\right]=-0.13\right.$ PLN, which represents $-0.1 \%$ of 119 PLN. When $q=4 \%$, then $S=\left[\begin{array}{c}119 \\ 98.5 \\ 25.51 \\ 7.54\end{array}\right]$ and consequently the cost of $\hat{x}_{3}$ is equal to $\left\langle S^{T} ; \hat{x}_{3}>=\left[\begin{array}{c}119 \\ 98.5 \\ 25.51 \\ 7.54\end{array}\right]\left[\begin{array}{c}0.009 \\ 0.200 \\ -1.001 \\ 0.700\end{array}\right]=0.23\right.$ PLN, which represents only $0.2 \%$ of 119 PLN. The calculations above can be summarized in 
Table 3. Theoretical value of portfolio $\hat{x}_{3}$ in 3 different scenarios

\begin{tabular}{c|c|c}
\hline $\mathrm{q}=2 \%$ & $\mathrm{q}=3 \%$ & $\mathrm{q}=4 \%$ \\
\hline cost of $\hat{x}_{3}=-0.76 \mathrm{PLN}$ & cost of $\hat{x}_{3}=-0.13$ PLN & cost of $\hat{x}_{3}=0.23$ PLN \\
\hline
\end{tabular}

Corollary 4. The costs of acquiring on June 1, 2015 hedging portfolios $\hat{x}_{1}, \hat{x}_{2}$ and $\hat{x}_{3}$ are close to 0 PLN, depending on dividend yield (q) paid annually by KGHM. Six months later these portfolios plus 1 KGHM's share secure payments close to 119 PLN, the latter being the price of 1 KGHM's share on June 1, 2015.

\section{Concluding Remarks}

The natural question arises how the level of volatility of share prices affects valuation of hedging portfolios, for example portfolio $\hat{x}_{3}$. Suppose therefore that volatility of KGHM's share prices is now lower, namely $\sigma=20 \%$, with other parameters remaining the same. Arguing in the same way as above, assume first that $\mathrm{q}=2 \%$. Then $\mathrm{d}_{1}=1,681$, $\mathrm{d}_{2}=1,540$ and consequently $\mathrm{N}\left(\mathrm{d}_{1}\right)=0,954, \mathrm{~N}\left(\mathrm{~d}_{2}\right)=0,9382$ so that by virtue of formula (4) we have $c_{95}=24,33$ PLN.

When dividend yield is higher, for example, $\mathrm{q}=3 \%$, then $\mathrm{d}_{1}=1,646, \mathrm{~d}_{2}=1,504$ and $\mathrm{N}\left(\mathrm{d}_{1}\right)=0,950, \mathrm{~N}\left(\mathrm{~d}_{2}\right)=$ 0,9338 so that $c_{95}=23,77$ PLN. Finally, when $q=4 \%$ then $d_{1}=1,610, d_{2}=1,1469$ and consequently $N\left(d_{1}\right)=$ $0,946, \mathrm{~N}\left(\mathrm{~d}_{2}\right)=0,9291$ so that the call option is even more cheaper, namely it costs $c_{95}=23,22 \mathrm{PLN}$. We have just proved the following

\section{Fact 2.}

The change of parameter q from $2 \%$ to $3 \%$ and next to $4 \%$ implies the corresponding change (decline) of $c_{95}$ :

\begin{tabular}{c|c|c}
\hline $\mathrm{q}=2 \%$ & $\mathrm{q}=3 \%$ & $\mathrm{q}=4 \%$ \\
\hline$c_{95}=24.33 \mathrm{PLN}$ & $c_{95}=23.77 \mathrm{PLN}$ & $c_{95}=23.22 \mathrm{PLN}$ \\
\hline
\end{tabular}

Now, using formula (6) instead of (4), we obtain the following results

\begin{tabular}{cccc}
\hline$\sigma=20 \%$ & $\mathrm{q}=2 \%$ & $\mathrm{q}=3 \%$ & $\mathrm{q}=4 \%$ \\
\hline put option & $\mathrm{p}_{110}=2.81$ PLN & $\mathrm{p}_{110}=2.97$ PLN & $\mathrm{p}_{110}=3.13$ PLN \\
\hline & {$[119]$} & &
\end{tabular}

When $\mathrm{q}=2 \%$, then the price vector $\mathrm{S}=\left[\begin{array}{c}119 \\ 98,5 \\ 24.33 \\ 2.81\end{array}\right]$. It implies that cost of portfolio $\hat{x}_{3}$ is below zero, namely $\left[\begin{array}{c}119 \\ 98,5 \\ 24.33 \\ 2.81\end{array}\right]^{T} \cdot\left[\begin{array}{c}0.009 \\ 0.200 \\ -1.001 \\ 0.700\end{array}\right]=-1.616$ PLN. When $\mathrm{q}=3 \%$, then the price vector $\mathrm{S}=\left[\begin{array}{c}119 \\ 98.5 \\ 23.77 \\ 2.97\end{array}\right]$ and consequently the theoretical price of $\hat{x}_{3}$ equals $\left[\begin{array}{c}119 \\ 98.5 \\ 24.33 \\ 2.81\end{array}\right]^{T} \cdot\left[\begin{array}{c}0.009 \\ 0.200 \\ -1.001 \\ 0.700\end{array}\right]=-0.944$ PLN. Finally, when $\mathrm{q}=4 \%$ the cost of $\hat{x}_{3}$ is equal to $\left[\begin{array}{c}119 \\ 98.5 \\ 23.22 \\ 3.13\end{array}\right]^{T}\left[\begin{array}{c}0.009 \\ 0.200 \\ -1.001 \\ 0.700\end{array}\right]=-0.281$ PLN

Corollary 2. When dividend q increases from $2 \%$ to $3 \%$ and next to $4 \%$, the negative theoretical cost of acquiring the

best approximate portfolio $\hat{x}_{3}$ is going up from -1,616 PLN to -0,944 PLN and next increases by almost the same amount to $-0,281$ PLN.

Comparing these negative prices of replicating portfolio $\hat{X}_{3}$ with those shown in table 3 when $\sigma$ equaled $35 \%$, one sees that lower volatility $(\sigma=20 \%)$ caused lower theoretical prices of $\hat{x}_{3}$.

Open Problem. (i) Is the same true for replicating portfolios $\hat{x}_{1}$ and $\hat{x}_{2}$ ?

(ii) Do always theoretical prices of replicating portfolios built by means of the methodology presented above decrease along with volatility of share prices?

\section{Reference}

Cerny, A. (2009). Mathematical https://doi.org/10.1515/9781400831487

Techniques in Finance. Princeton University Press. 
pl.investing.com/equities/kghm-polska-miedz-sa-historical-data

Zaremba, L. (2016). Replication of financial instruments which compensate lower share prices, Economic Studies (Studia Ekonomiczne), 90(3), 502-511.

Zaremba, L. (2017a). Creation and valuation of instruments compensating lower share prices with the help of Black-Scholes formula. Foundations of Management, 9(17), 25-32. https://doi.org/10.1515/fman-2017-0002

Zaremba, L. (2017b). Inżynieria finansowa na rynkach niezupełnych, (Financial Engineering in the Incomplete Markets). Kwartalnik Naukowy Uniwersytetu Vistula (Vistula Scientific Quarterly), 53(3), 117-129.

Zaremba, L. Portfolios which compensate lower share prices without short sale of shares, Zeszyty Naukowe Uniwersytetu Vistula (Vistula Research Papers), (in press).

\section{Copyrights}

Copyright for this article is retained by the author(s), with first publication rights granted to the journal.

This is an open-access article distributed under the terms and conditions of the Creative Commons Attribution license which permits unrestricted use, distribution, and reproduction in any medium, provided the original work is properly cited. 